The services provided by first responders could be enhanced greatly by training and close supervision through integrated mass-casualty management plans in developing countries. Keywords: Asia; dead bodies; disaster; disaster management; first responders

Prehosp Disast Med 2009;24(2):s20-s21

\section{Disaster Needs Assessment Teams: Recent Experiences} in Australia

Andrew Robertson; Tarun Weeramantbri

Public Health Division, Western Australian Department of Health, East Perth, Western Australia Australia

Introduction: Historically, Australia has relied on the Australian Defence Force to provide overseas medical assistance, including early disaster needs assessment. The need for small, rapidly deployable disaster needs assessment teams has been highlighted from experience gained from deploying civilian medical teams to Maldives and Banda Aceh after the 2004 tsunami; Yogyakarta after the 2006 earthquake, and aircraft crash in 2007; and to Mumbai after the bombings in 2008.

Methods: In previous disaster responses, the selection and preparation of these teams have been ad hoc, depending on the availability of suitable people to deploy. The Western Australian Department of Health, as part of its piloting of Australian Medical Assessment Teams (AUSMATs) development, has identified the need, composition, preparation, and training required for these small teams on a national basis.

Results: This presentation will examine the need, requirements, and development of these assessment teams; their communication role in the early stages of a disaster response and their role in facilitating the deployment of appropriately tasked, equipped, and trained Australian medical teams to assist in the disaster response. Recent deployments to Yogyakarta and Mumbai have illustrated the issues encountered if these teams are utilized.

Conclusions: The further development of these teams nationally is an ongoing focus. It is anticipated that a number of these teams will be prepared and ready to respond by the end of 2009.

Keywords: Australia; disaster health management; disaster needs assessment teams Prehosp Disast Med 2009;24(2):s21

Creating an Advanced Medical Assistance Station for the Emergency Medical Assistance Service in French Guiana

Gerald Egmann; ${ }^{1}$ Jean Laversanne; ${ }^{1}$ Tbierry le Guen; ${ }^{1}$ Michel Durand, ${ }^{2}$ Antonio Guel ${ }^{3}$

1. SAMU de Guyane, Cayenne, France

2. Thales Alenia Space Company, Cannes, France

3. Centre National d'Etudes Spatiales, Paris, France

Introduction: French Guiana is a sparsely populated French department in South America. Ninety percent of its territory is covered with dense, equatorial rainforests. Medical teams constantly are confronted with difficulties concerning access for emergency services and telecommunications.

Methods: The Emergency Medical Assistance Service of French Guiana (SAMU973) is working with the French
National Spatial Agency and Thales-Alenia-Space Company to develop a high-tech, autonomous tool for tropical environments that can be deployed easily in disaster areas or isolated regions.

This unit, known as the Advanced Medical Assistance Station (PSMA) comes in a form of a freight container that can be transported by land, sea, or air, and contains communications equipment (tactical radio communications network, satellite dish, and computerized videoconference equipment) and peripheral applications that can be installed easily by a small, autonomous team.

Results: After being tested using three simulations in an isolated area, the PSMA demonstrated its efficiency for reconnaissance missions. It also can be used to coordinate the emergency medical chain and support medical teams operating field hospitals during longer missions. This is done using its communications networks, portable telemedicine unit for triaging and monitoring victims, and system for identifying and monitoring large numbers of patients (using barcodes).

Conclusions: The final results will provide French Guiana and the SAMU973 with an efficient disaster management facility able to withstand tropical conditions that is easy to deploy when aiding disaster victims.

Keywords: disaster management; French Guiana; isolated areas; medical care; transmission; triage

Prehosp Disast Med 2009;24(2):s21

Replication of a Study on Disaster Myths among Students in a Graduate Course on an Introduction to Emergency Preparedness and Disaster Health

Frank Archer

Monash University, Department of Community Emergency Health and Paramedic Practice, Frankston, Victoria Australia

Introduction: Recently, de Goyet, Alexander, and Auf der Heide each have written on "disaster myths". Alexander presents disaster myths as "propositions" and used them in a study to ascertain an understanding of these myth by students in Europe. Auf der Heide used an evidence-based approach to develop a similar list of myths. The purpose of this study was to explore the understanding of myths by two groups of Australian graduate health professionals.

Methods: Alexander's 19 propositions on disaster myths were replicated in a similar questionnaire. A further seven propositions from Auf der Heide were added. The questionnaire was distributed on two occasions to two groups of graduate health professionals undertaking the introductory unit in a Graduate Certificate in Emergency Preparedness and Disaster Health. The first occasion was during the first session in the course. The second was during the last session of the course, without any specific feedback on the outcomes of the first attempt.

Results: The means for all propositions for both groups of students in the initial attempt were in the "neutral" or "agree" range, while they should have been in the "strongly disagree" or "disagree" range. This profile was similar to the results found by Alexander. The means for all propositions for both groups of students in the second attempt also were in the "neutral" or "agree" range, although more were in the "neutral" range. Only a few students recognized the impli- 